\title{
COMPARISON OF SONOGRAPHY AND COMPUTED TOMOGRAPHY IN ANALYSIS OF ORBITAL SPACE- OCCUPYING LESIONS
}

\author{
Sumathy Soundararajan ${ }^{1}$, Ravichandran Sathianarayanan ${ }^{2}$, N. Rammurugan ${ }^{3}$ \\ 1 Professor and HOD, Department of Radiodiagnosis, Government Rajaji Hospital, Madurai. \\ 2Professor, Department of Radiodiagnosis, Madurai Medical College, Madurai. \\ ${ }^{3}$ Senior Assistant Professor, Institute of Microbiology, Madurai Medical College, Madurai.
}

\section{ABSTRACT}

\section{BACKGROUND}

Orbital space-occupying lesions presenting mainly with proptosis is one of the interesting conditions in Ophthalmology and poses a challenge for diagnosis and management. This study was undertaken to compare the contributions of the two vital techniques, Computed Tomography and Ultrasound in characterisation of the offending condition. The merits of each method was demonstrated relative to defining the location, extension, and nature of the lesion.

\section{MATERIALS AND METHODS}

Eighty patients with a strong clinical suspicion of intraorbital space-occupying lesions were included in this descriptive study. USG was first done when the suspicion was strongly in favour of intraocular lesions due to clinical presentation (Leucocoria) or ophthalmoscopic findings. Other cases were subjected to CT initially and then correlated with ultrasound. Final diagnosis made in correlation with HPE/therapeutic trial, etc.

\section{RESULTS}

Eighty Patients in the age group of 21 days to 60 years were included in the study. The results were analysed under two categories - the space occupying lesions of the eyeball and intraorbital extraocular space occupying lesions. Only 10 patients were included in the first group. Children formed the majority and retinoblastoma was the commonest presentation. Good sensitivity was noted with both modalities regarding ocular and orbital extension of Retinoblastoma (100\%). The second group namely orbital lesions included optic Nerve lesions, vascular masses, pseudotumour and muscular lesions. Primary paranasal masses and bony orbital lesions presenting with proptosis were also included in the study. Sonography was found to be excellent for the diagnosis of optic nerve lesions and vascular masses but it had to be supplemented with CT to delineate the extent of the mass for the rest of lesions.

\section{CONCLUSION}

Sonography is found to be a sensitive modality for intraocular lesions, but CT proved its supremacy in characterisation of extraocular lesions, including bony lesions, paraorbital lesions and cystic masses.

\section{KEYWORDS}

Orbital Space-occupying Lesions, USG, CT, Comparison.

HOW TO CITE THIS ARTICLE: Soundararajan S, Sathianarayanan R, Rammurugan N. Comparison of sonography and computed tomography in analysis of orbital space-occupying lesions. J. Evolution Med. Dent. Sci. 2017;6(74):5308-5313, DOI: 10.14260/Jemds/2017/1152

\section{BACKGROUND}

Orbital space-occupying lesions presenting mainly with proptosis is one of the interesting and panicky situation and poses a challenge in both diagnosis and management. Inaccessibility of the contents of the orbit makes the role of the radiologist very vital especially because of the advancement in the imaging tools which portray the orbit and its contents exquisitely well, but only few reports have considered the relative merits of each technique. Study group includes diverse age groups. No racial/age/sex predilection was observed.

Financial or Other, Competing Interest: None.

Submission 20-07-2017, Peer Review 01-09-2017,

Acceptance 08-09-2017, Published 14-09-2017.

Corresponding Author:

Dr. Ravichandran Sathianarayanan,

Professor,

Department of Radiodiagnosis,

Government Rajaji Hospital,

Madurai.

E-mail: drsravichandran@gmail.com

DOI: $10.14260 /$ jemds $/ 2017 / 1152$
In ocular lesions, retinoblastoma contributed $62 \%$. Pseudotumour and TRO (Thyroid Ophthalmopathy) formed $35 \%$ of orbital lesions. We have tried to assess which technique helps to characterise the lesion best to help the physician to proceed with management. Accurate diagnosis is important because a short therapeutic course can give immense relief to patients in cases of Thyroid ophthalmopathy, Pseudotumour, Orbital cellulitis, etc. (which constitutes $42 \%$ ).

\footnotetext{
Aim of the Study

We tried to compare the contributions of the two vital techniques, Computed Tomography and Ultrasound in characterisation of the offending condition. We tried to determine as to which technique i.e. Computerised Tomography or Ultrasonography (B-mode with High Frequency $-7 \mathrm{MHz}$ for the globe, $3 \mathrm{MHz}$ for Retrobulbar area and Colour Doppler) improves the characterisation and topography for that particular condition. We also tried to assess the technique which identifies the secondary effects of the mass on the soft tissue and bone.
} 


\section{MATERIALS AND METHODS}

This was a descriptive study. The study was conducted in Government Rajaji Hospital, Madurai. This study has been conducted from Jan. 2014 to Jan. 2016. Eighty patients in the age group ranging from 21 days to 60 years with a strong clinical suspicion of intraorbital space-occupying lesions were subjected to the study. High frequency transducer 5 $\mathrm{MHz}, 10 \mathrm{MHz}$ probes have revolutionised ocular \& orbital evaluation. Natural high-density differences between the orbital structures \& surrounding fat makes the orbit an ideal subject for evaluation by CT besides elucidation of contrast enhancement. Window adjustments and evaluation of orbital apex are additional advantages with CT.

\section{CT Techniques}

All patients were scanned on Toshiba Asteion 4 slice - CT scanner (with 0.75 seconds scan time) and Wipro GE SytecSRi-Single slice -CT Scanner. Scans were obtained at $3 \mathrm{~mm}$ intervals with $3 \mathrm{~mm}$ collimation from the floor of the anterior cranial fossa to the maxillary sinus along the axial plane and from the region of optic strut level to the preseptal space along the coronal plane $(\mathbf{1}, \mathbf{2}, \mathbf{3 , 4}, \mathbf{5})$. Intravenous contrast was used in majority of cases and contrast enhancement was observed. The topography of any mass was noted. Exact localisation with respect to the four spaces i.e. Tenon's space, Central orbital space (Area within the muscle cone). Peripheral orbital space (between the periosteum and extraocular muscle). Subperiosteal space (limited by Periosteum) was made out. The size, margins, density value, homogeneity, calcification, extent, infiltration and contrast enhancement were noted. The most probable diagnosis was offered after correlating with clinical presentation and ultrasound.

\section{Ultrasound}

All patients were scanned by Esaote Biomedica $(7 \mathrm{MHz}$ and 5 $\mathrm{MHz}$ ), Synergy (Doppler $-3 \mathrm{MHz}$ ) \& Aloka Prosound 4000. Colour Doppler was employed in relevant cases and vascular pattern was noted. As with CT the size, location, reflectivity, calcification and vascularity were noted.

USG was first done when the suspicion was strongly in favour of intraocular lesions due to clinical presentation (Leucocoria) or ophthalmoscopic findings. Other cases were subjected to CT initially and then correlated with ultrasound. Masses that were evaluated adequately by CT (which included orbital sphenoidal meningiomas and carcinomas originating from the sinuses or nasopharynx) did not undergo sonography; each patient had all studies on the same day. The studies were interpreted by two different radiologists, who were aware of the clinical findings but not of the other procedure. Surgery was performed in 20 cases, and allowed an exact tomographic and histologic diagnosis. Biopsy was performed before treatment (medical, surgical, or radiation) in 10 cases to assess a doubtful diagnosis. In cases of lymphoma, pseudotumour, Graves' disease, and orbital cellulitis (31 cases), diagnosis was assessed by a clinical followup after medical treatment. For all these cases, the final diagnosis was established either by histology (surgery, biopsy, or specimen) or by a clinical followup when there was medical treatment.

\section{Ethical Approval}

Approval was obtained from hospital authorities though it involves non-invasive modalities.

\section{RESULTS}

Eighty Patients in the age group of 21 days to 60 years were included in the study. It included 48 males (52\%) and 32 females (48\%). Majority of the patients were in the age group of $20-30$ and $50-60$ (Table-1). The common presenting complaints were proptosis and eye pain associated with headache. The results were analysed under two categories the space occupying lesions of the eyeball and intraorbital extraocular space occupying lesions.

\begin{tabular}{|c|c|c|}
\hline $\begin{array}{c}\text { Age Groups } \\
\text { (In years) }\end{array}$ & $\begin{array}{c}\text { Number of } \\
\text { Patients(N=80) }\end{array}$ & Percentage \\
\hline $0-10$ & 10 & 12.50 \\
\hline $10-20$ & 13 & 16.25 \\
\hline $20-30$ & 16 & 20.0 \\
\hline $30-40$ & 10 & 12.5 \\
\hline $40-50$ & 15 & 18.75 \\
\hline $50-60$ & 16 & 20.0 \\
\hline \multicolumn{3}{|c|}{ Table 1 } \\
\hline
\end{tabular}

\section{Category 1. Space occupying Lesions of the Eyeball Ten Patients belonged to the I Category}

The diagnostic approach is different for adults and children. In children the primary problem is retinoblastoma, and in adults melanoma and metastases occur commonly.(6,7). Our pediatric eyeball lesions are tabulated as follows (Table 2).

\begin{tabular}{|l|c|c|c|}
\hline Parameter Considered & N & Sonography & CT \\
\hline \multicolumn{1}{|c|}{ Recognition of Mass } & 8 & $8(100 \%)$ & $8(100 \%)$ \\
\hline Recognition of Extension & & & \\
\hline A. Extraocular & 2 & $2(100 \%)$ & $2(100 \%)$ \\
\hline B. Brain & 2 & $0(0 \%)$ & $2(100 \%)$ \\
\hline $\begin{array}{l}\text { C. Identification of } \\
\text { nature }\end{array}$ & 8 & $8(100 \%)$ & $8(100 \%)$ \\
\hline
\end{tabular}

Table 2. Sonography and CT for Studying Eyeball Lesions in Children

We had 8 cases of intraocular mass lesions in children. All of them presented with leucocoria. We identified retinoblastoma (Image 1a, b) in 5 cases, 1 case of PHPV, Coats disease and one case of intraocular bleed due to aplastic anaemia. The tell-tale pattern of calcification in retinoblastoma which is multifocal, varying size and subretinal location helped to narrow down the diagnosis and to differentiate it from its mimics such as PHPV and Coat's disease. Extraocular extension (i.e.) optic nerve invasion was reported in 2 cases both by US and CT which was confirmed at surgery. So the patient was subjected to RT after enucleation. Intracranial metastasis was identified in two cases by CT (which includes the youngest of the study group 16 days) which was missed at orbital ultrasound (Image 2). A case of bilateral retinoblastoma was identified and the progress of the lesion in the unoperated eye was demonstrated well by both CT and U/S. One was a case of trilateral retinoblastoma with suprasellar lesion. Both the techniques demonstrated the bulbar lesions in two cases of Cryptophthalmos, which had congenital cystic eyeball (Image 3a \&b). Mobile intraocular echoes in the case of aplastic anaemia supported by hyperdense layer in CT confirmed the clinical suspicion of intraocular bleed. The recognition of a 
mass in the eyeball was accomplished by both CT and sonography in all cases, and identification of lesion type was equal for both procedures. Intraorbital extension was recognised equally by both examinations, but brain extension of retinoblastoma was recognised by CT only.

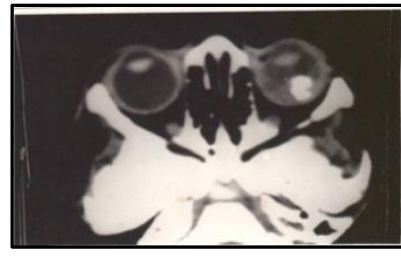

Image 1a

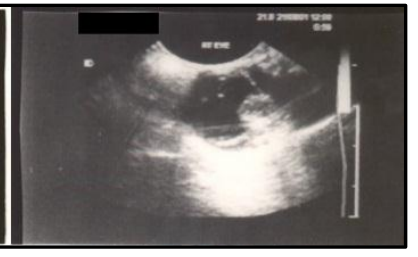

Image 1b

Figure 1a-Retinoblastoma CT image showing hyperdense mass lesion in the temporal aspect of posterior segment of left globe with areas of calcification- tell-tale sign.

Figure 1b- U/S imaging showing the endophytic form of retinoblastoma with retinal detachment.

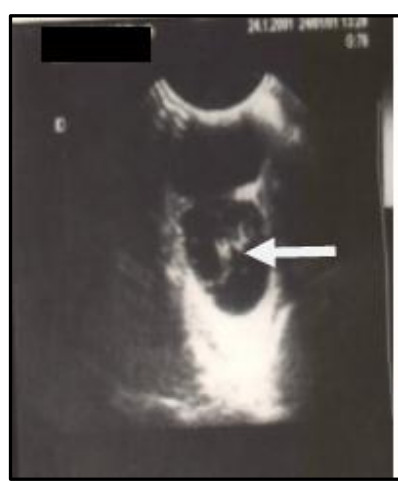

Image 2a

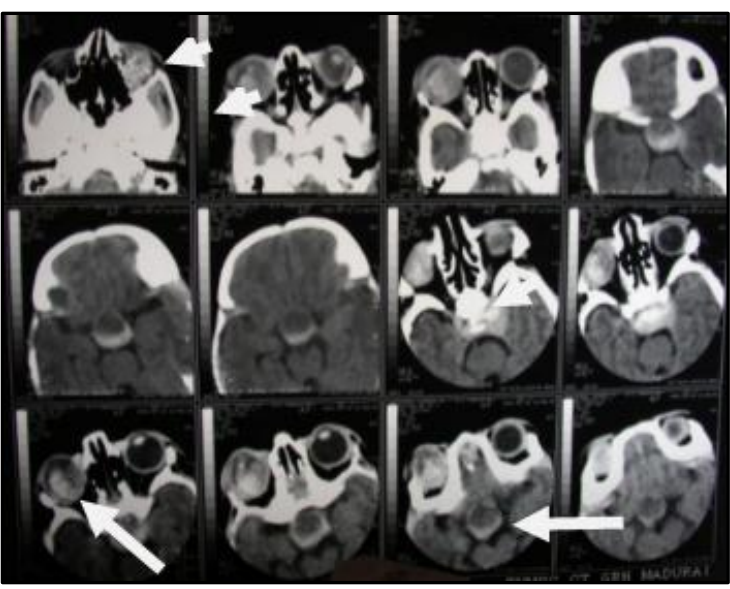

Image 3

Figure 2a and 2b- Congenital cystic eyeball. Axial scan CT and USG image of child with Cryptophthalmos showing features of a cyst with poor differentiation of globe. Internal features of cyst well delineated with sonography.

Figure 3- Trilateral retinoblastoma- Serial axial section demonstrates lesion in both globes and suprasellar region.

Our adult population showed a different statistical data. Though many adult patients were subjected to ultrasound after ophthalmoscopic examination, only two patients among the adult population could be included in the study under this category, because most of them (Melanoma and Osseous choristoma) were operated based on the clinical and sonography examination as intraocular masses rarely spread to brain. Our case of melanoma did not show extraocular extension. Results are as follows. (Table 3 ).

\begin{tabular}{|c|c|c|c|}
\hline Parameter Considered & No & Sonography & CT \\
\hline Recognition of Mass & 2 & $2(100 \%)$ & 1 \\
\hline Recognition of Extension & - & & \\
\hline Identification of Nature & 2 & $2(100 \%)$ & 1 \\
\hline \multicolumn{4}{|c|}{ Table 3. Sonography and CT for Studying Space } \\
Occupying Lesions in the Eyeball of Adults \\
\hline
\end{tabular}

It is obvious from the table that the intraocular masses in adults were recognised by sonography in $100 \%$ of cases, but by CT in only $50 \%$. The type of lesion was identified by sonography in $100 \%$ of cases, but by CT in only $50 \%$. In adults, intraocular masses were identified more accurately by sonography than by CT.

\section{Category. Extraocular Intraorbital space-occupying} lesions.

\section{Seventy Patients belonged to the II Category}

The group comprised of 6 Optic Nerve lesions (2 Meningioma, 1 Sciıwannoma, 1 glioma and 2 calcified granulomas), 7 vascular masses (a case of varix, 1 Arteriovenous Malformation, 5 cavernous haemangiomas), 12 cases of pseudotumour, 5 cystic lesions (dermoid cyst-3, chronic haematic cyst-2), 3 cases of metastasis, 12 muscular lesions of which 8 were suggestive of thyroid ophthalmopathy. Four lacrimal gland lesions (adenoma 2, a lymphoma and a pseudotumour) were characterised. We had 6 cases of orbital cellulitis (two of them were in stage III). 3 cases of trauma had subperiosteal haematoma. Six cases of primary paranasal masses had orbital extension. We had 6 bony orbital lesions (sphenoid wing meningioma, psammomatous meningioma of the ethmoid, fibrous dysplasia of superior orbital wall, reparative giant cell granuloma of maxilla, etc.).

\section{Intraorbital Mass Lesions}

\begin{tabular}{|c|c|c|c|}
\hline \multirow{2}{*}{$\begin{array}{l}\text { Parameter } \\
\text { Considered }\end{array}$} & \multirow{2}{*}{\begin{tabular}{|c|} 
Total No. \\
of Lesions \\
$(n=70)$ \\
\end{tabular}} & \multicolumn{2}{|c|}{ n, \% } \\
\hline & & Sonography & CT \\
\hline Recognition of mass & \multirow{5}{*}{58} & $58(100 \%)$ & $58(100 \%)$ \\
\hline $\begin{array}{c}\text { Location relative to } \\
\text { eyeball }\end{array}$ & & $47(82 \%)$ & $58(100 \%)$ \\
\hline $\begin{array}{c}\text { Location relative to } \\
\text { muscle cone. }\end{array}$ & & $47(82 \%)$ & $58(100 \%)$ \\
\hline $\begin{array}{c}\text { Characterisation } \\
\text { (vascularity\& } \\
\text { composition) }\end{array}$ & & $35(60 \%)$ & 55 (95\%) \\
\hline $\begin{array}{l}\text { Full extent \& bony } \\
\text { involvement }\end{array}$ & & $35(60 \%)$ & 55 (95\%) \\
\hline $\begin{array}{c}\text { Others } \\
\text { Paranasal sinus } \\
\text { lesions }\end{array}$ & 6 & $14.5(25 \%)$ & $6(100 \%)$ \\
\hline Bony orbital lesions & 6 & $1(16 \%)$ & $6(100 \%)$ \\
\hline $\begin{array}{r}\text { Table 4. Son } \\
\text { Extrao } \\
\end{array}$ & aph & $\begin{array}{l}\text { CT for Stu } \\
\text { f the Orbi }\end{array}$ & \\
\hline
\end{tabular}

Recognition and exact localisation of the mass were done accurately by both modalities in all our cases. The true extent of the mass and bony involvement was evaluated by CT accurately. The localisation with respect to muscle cone is 
better resolved by CT (esp.) coronal scans though ultrasound does not lag behind in this aspect.

\begin{tabular}{|c|c|c|c|c|}
\hline Lesion & $\mathbf{n}$ & $\begin{array}{c}\text { \% Detected } \\
\text { by Sono- } \\
\text { graphy }\end{array}$ & CT & $\begin{array}{c}\text { Sono- } \\
\text { graphy \& } \\
\text { CT }\end{array}$ \\
\hline $\begin{array}{c}\text { Optic nerve } \\
\text { masses }\end{array}$ & 6 & $6(100 \%)$ & $5(75 \%)$ & $100 \%$ \\
\hline Vascular & 7 & $6(85 \%)$ & $6(85 \%)$ & $85 \%$ \\
\hline Pseudotumour & 12 & $6(50 \%)$ & $10(88 \%)$ & $88 \%$ \\
\hline Cystic Lesions & 5 & $1(16 \%)$ & $5(100 \%)$ & $100 \%$ \\
\hline Metastases & 3 & $-(0 \%)$ & $3(100 \%)$ & $100 \%$ \\
\hline Trauma & 3 & $-(0 \%)$ & $3(100 \%)$ & $100 \%$ \\
\hline $\begin{array}{c}\text { Muscular } \\
\text { lesions(TR0) }\end{array}$ & 12 & $12(100 \%)$ & $12(100 \%)$ & $100 \%$ \\
\hline $\begin{array}{c}\text { Lacrimal gland } \\
\text { Lesions }\end{array}$ & 4 & $2(50 \%)$ & $4(100 \%)$ & $100 \%$ \\
\hline Orbital Cellulitis. & 6 & $1(16 \%)$ & $6(100 \%)$ & $100 \%$ \\
\hline $\begin{array}{r}\text { Table 5. Characterisation of Masses, Accuracy of } \\
\text { Sonography and CT in Identifying }\end{array}$ \\
\hline \multicolumn{5}{|c|}{}
\end{tabular}

The exact location of the lesion relative to the optic nerve was identified slightly better with sonography, because it could detect a small layer of fat between the mass and the nerve that could not be demonstrated by CT in some cases of large intraorbital tumours, and because the acoustic impedance is much different between the optic nerve and any type of mass lesion.

Regarding vascular masses, sonography is better than CT because of its dynamic features. In cavernous angiomas, the honeycomb pattern of sonography is characteristic (fig. 3) as are the other kinetic sonographic features. In varices, enlargement of the mass during the Valsalva manoeuvre was demonstrated more readily by sonography than by CT. CT was found to be better in evaluation of arteriovenous malformations and carotid cavernous fistula.

As regards to bony lesions and paraorbital masses sonography failed and CT's supremacy has been established by this study. For bony lesions, CT had an accuracy of $100 \%$, while sonography had only $16 \%$ (Table 4 and 5).

It is evident from this table that CT excels sonography in evaluation of orbital lesions and combined use of them increases accuracy.

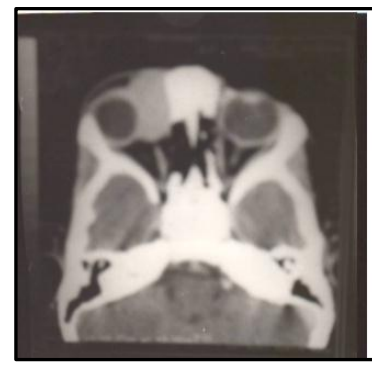

Image 4a. CT

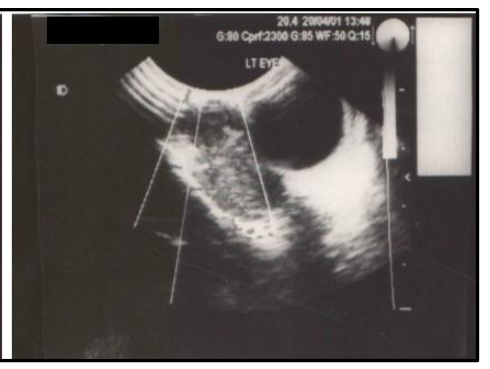

Image 4b. USG
Figure 4a. Rhabdomyosarcoma. CT axial section - welldefined, enhancing lobulated lesion in extraconal space on medial aspect of Lt orbit in a child -Provisional Diagnosis, Cavernous haemangioma.

Figure 4b. USG - Consistent with vascular tumour - HPE proved as Rhabdomyosarcoma.

An attempt was made to determine as to which the best modality in identifying the malignant nature of the mass is. (Table 6).

\begin{tabular}{|c|c|c|c|c|}
\hline \multirow{2}{*}{ Lesion } & \multirow{2}{*}{$\begin{array}{c}\text { Total } \\
\text { (n) }\end{array}$} & Sonography & CT & $\begin{array}{c}\text { Sonography } \\
\text { \&CT }\end{array}$ \\
\hline Benign & 50 & $32(65 \%)$ & $50(100 \%)$ & $50(100 \%)$ \\
\hline Malignant & 8 & $0(0 \%)$ & $5(67 \%)$ & $5(67 \%)$ \\
\hline Table 6. Sonography and CT in Identifying Benign and \\
Malignant Extraocular Masses in the Orbit Excluding \\
Paranasal Masses and Bony Lesions \\
\hline
\end{tabular}

There were 8 malignant lesions. It is clear from the above table that CT identifies the malignant features of the mass (Obliteration of fascial planes and bony involvement) better than Sonography. This was especially true for metastases, A case diagnosed as cavernous haemangioma was proved to be rhabdomyosarcoma at biopsy (Image 4a, b). CT and Ultrasound failed in this case as the lesion was well circumscribed. Sonography reflects histology, hence combined use of CT and U/S is expected to increase the accuracy. But in this case ultrasound features were only suggestive of a highly vascular mass and thus failed.

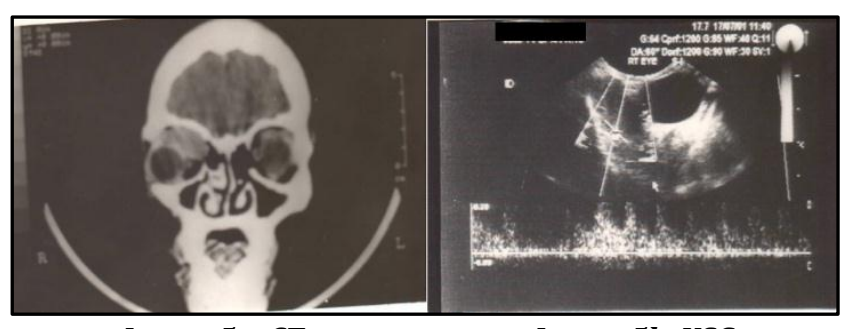

Image 5a. CT

Figure 5a- Cavernous haemangioma. CT coronal section Extraconal mass lesion in superior aspect of right orbit Figure 5b- USG. Vascularity noted- biopsy proven case.

Statistical Analysis is as follows-

\begin{tabular}{|c|c|c|c|c|}
\hline & \multicolumn{2}{|c|}{ SONOGRAPHY } & \multicolumn{2}{c|}{ CT } \\
\hline Statistics & Value & $\mathbf{9 5 \%}$ CI & Value & $\mathbf{9 5 \% \text { CI }}$ \\
\hline Sensitivity & $95.12 \%$ & $\begin{array}{c}83.47 \% \text { to } \\
99.40 \%\end{array}$ & $97.47 \%$ & $\begin{array}{c}91.15 \% \text { to } \\
99.69 \%\end{array}$ \\
\hline Specificity & $100.00 \%$ & $\begin{array}{c}88.06 \% \text { to } \\
100.00 \%\end{array}$ & $100.00 \%$ & $\begin{array}{c}29.24 \% \text { to } \\
100.00 \%\end{array}$ \\
\hline $\begin{array}{c}\text { Positive } \\
\text { Likelihood } \\
\text { Ratio }\end{array}$ & & & & \\
\hline $\begin{array}{c}\text { Negative } \\
\text { Likelihood } \\
\text { Ratio }\end{array}$ & 0.05 & $\begin{array}{c}0.01 \text { to } \\
0.19\end{array}$ & 0.03 & $\begin{array}{c}0.01 \text { to } \\
0.10\end{array}$ \\
\hline $\begin{array}{c}\text { Disease } \\
\text { prevalence }\end{array}$ & $58.57 \%\left(^{*}\right)$ & $\begin{array}{c}46.17 \% \text { to } \\
70.23 \%\end{array}$ & $96.34 \%\left(^{*}\right)$ & $\begin{array}{c}89.68 \% \text { to } \\
99.24 \%\end{array}$ \\
\hline $\begin{array}{c}\text { Positive } \\
\text { Predictive } \\
\text { Value }\end{array}$ & $100.00 \%$ & $\left(^{*}\right)$ & $100.00 \%$ & $(*)$ \\
\hline $\begin{array}{c}\text { Negative } \\
\text { Predictive } \\
\text { Value }\end{array}$ & $93.55 \%\left(^{*}\right)$ & $\begin{array}{c}78.96 \% \text { to } \\
98.25 \%\end{array}$ & $60.00 \%\left(^{*}\right)$ & $\begin{array}{c}27.63 \% \text { to } \\
85.49 \%\end{array}$ \\
\hline
\end{tabular}

\section{DISCUSSION}

Ultrasound and computed tomography have been deployed in imaging the orbit as early as 1975 and each modality has its own merits and demerits.

Berger(8) et al has observed $100 \%$ accuracy by both modalities in recognition of intraocular mass lesions in children. His study has proved beyond doubt the efficacy of $\mathrm{CT}$ in detection of intracranial extension. Both CT and U/S are 
equally good in detecting intraorbital (optic nerve) extension. The findings in our study also correlated well with his observation. In adults the score for sonography increases even more as even malignant masses in adults hardly extend intracranially. The characterisation of the intraocular mass is better with ultrasound. The most common intraocular mass in our study was retinoblastoma. Endophytic form was the commonest presentation. M. Kaufman ${ }^{(9)}$ of Chicago University also reported similar results. His study also proved that CT only can differentiate the atypical presentations of retinoblastoma from its mimics, (ex.) Coat's disease, Retinopathy of prematurity and PHPV. When there is a clinical or sonographic suspicion of extraocular extension, CT is very helpful in demonstrating the extent of this orbital extension though USG does not lag behind. For children, in whom the lesion often extends outside the eyeball and sometimes beyond the orbit, we recommend a different protocol i.e. Sonography should be performed first to rule out other causes of leucocoria. If the diagnosis of a retinoblastoma is positive or questionable, CT should be performed to rule out possible intracranial or intraorbital extension.

Among the extraocular orbital masses, vascular masses form an interesting group. Cavernous haemangiomas was intraconal in $71 \%$ cases as described in literature. They lack a capsule and show infiltrative features which makes it difficult to differentiate from malignant lesions as in our case (Image 4). Davis et al(8) has compared ultrasound with CT in evaluating angiomas and reported improved tissue specificity with ultrasound (honeycomb pattern of A-mode sonography is characteristic (Fig. 3), as are the other kinetic sonographic features) but better evaluation of apical extension is possible only with CT $(5 \mathrm{a}, \mathrm{b})$. Dynamic variations of the venous malformations with Valsalva manoeuvre or jugular vein compression are demonstrated by sonography as it is a real time examination. (Image 6a, b).

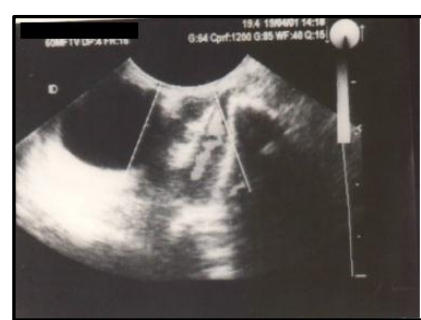

Image 6a. CT

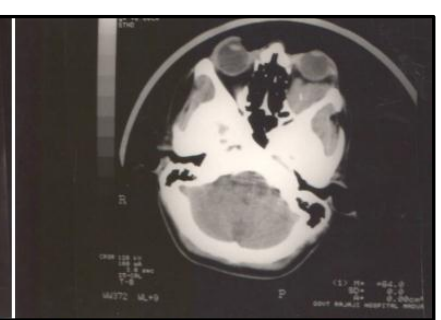

Image 6b. USG
Figure 6a- Orbital Varix CT Axial section- Lobulated lesion in inferior aspect of orbit.

Figure 6b- Postural variation in size noted along with dilated vein.

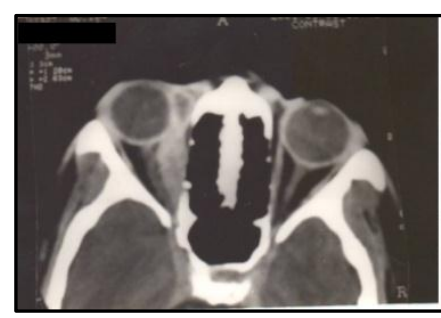

Image 7a. CT

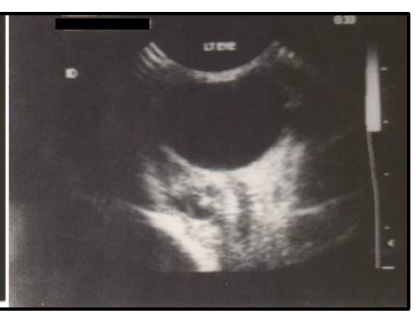

Image $7 b$. USG
Figure 7a-Myositic form of Pseudotumour CT axial section: Asymmetrically enlarged medial rectus with involvement of tendinous portion, in homogenous enhancement, and streaky densities.

Figure 7b- USG- ill-defined focal muscle enlargement and altered echoes. Diagnosis:- ? Cysticercus-biopsy proven as pseudotumour.

Though haemangioma can be identified even by USG scan by the characteristic honey comb appearance, caroticocavernous fistula and AV malformation require a contrast CT. Our study also fully correlated with this observation.

Lesions of the optic nerve include meningioma, glioma and granulomas. Gliomas present as diffuse enlargement of the optic nerve while commonly observed nerve sheath tumours and meningiomas may appear as an eccentric mass along the optic nerve. Glenn(10) S.Forbes, M.D.; Franklin Earnest IV, M.D.; and Robert R. Valler, M.D. of Mayo Clinic have found that though optic nerve tumours can be well demonstrated by thin slice axial scanning, coronal and sagittal views are most useful for showing continuous enlargement of the nerve. They also observed that marked contrast enhancement is more suggestive of primary optic nerve sheath meningioma. I.F. Moseley,(11) M.D., National Hospital London emphasised the role of sonography in optic nerve tumour evaluation. He claims that because the acoustic impedance of the mass is different from the nerve, tumours of the nerve can be easily identified and also any thin layer of intervening fat can be identified during real time examination. Neurofibromas are better characterised by CT as it picks up the bone expansion (due to its slow growth) and contrast enhancement. CT scores over USG in evaluating optic nerve lesion in our study.

Pseudotumour has a broad range of radiographic appearances. Dieter Enzman(12)and Donaldson, Stanford University have reported infiltrative form to be the most common presentation. However, myositic variety (92\%) formed the majority in our study (Image $7 \mathrm{a}, \mathrm{b}$ ). Tumefactive form $(8 \%)$ is often confused with a mass of different aetiology and biopsy is diagnostic in such cases. In our study, a case (tumefactive form) was reported as sarcoma but turned out to be pseudotumour at biopsy. The myositic form is often confused with Graves'. Though classical presentation of Graves' occurs in thyrotoxicosis patients it may occur even in euthyroid persons. Graves' ophthalmopathy usually presents as bilateral, symmetrical enlargement of the extraocular muscles associated with increase in retrobulbar fat volume. The globe, optic nerve and retrobulbar fat remain as distinct and normal structures in Graves'. Pseudotumour presents as streaky densities at these 3 sites. Pseudotumour involves the tendinous portion unlike Graves' which involves the bellies. Three out of four patients with TRO had normal thyroid profile, unilateral presentation and differentiation was made using the above said criteria.

The common benign lacrimal gland lesions are dermoids, granulomas and cysts. Malignant lesions include adenocarcinoma and cylindroma. Glenn S. Forbes(10) has reported that sonography is efficacious in recognising the mass but further characterisation requires CT. In our study, we had 3 benign lesions including a case of pseudotumour and a case of lymphoma. Both sonography and CT showed equal results though the smooth moulding of the mass to neighbouring structures was observed in CT. 
David L. Harr, M.D., Robert.M. Quencer(13), M.D., Miami School of Medicine compared computed tomography with ultrasound in evaluation of orbital infection and found that ultrasound despite its better resolving capacity added no additional clinical information and CT is mandatory in all suspected cases of orbital cellulitis. So ultrasound should be reserved only for followup of orbital infection to evaluate the response to therapy. Two out of six patients with orbital cellulitis had subperiosteal abscess and one of them had superior ophthalmic vein thrombosis. The true extent was assessed only by CECT and US was used for followup.

The masses arising from the bony orbital wall presenting as space occupying lesions were analysed by CT and the most probable pathological diagnosis was offered which was confirmed after surgery. USG failed in evaluation of these lesions. We had 6 cases of sinonasal tract masses invading the orbit. Except for a case of ethmoidal mucocoele which was demonstrated on $\mathrm{U} / \mathrm{S}$, all other lesions were characterised only by CT.

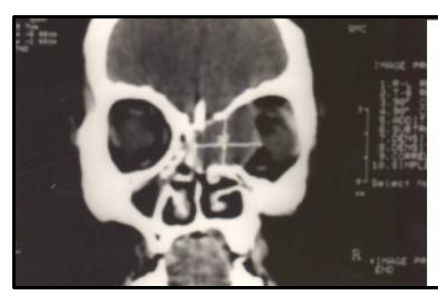

Image 7a. CT

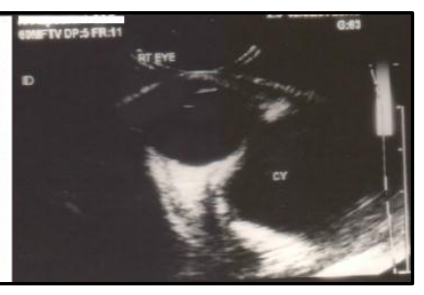

Image 7b. USG
Figure 8a- Ethmoidal Mucocoele. CT PNS- Coronal sectionExpansile lesion along the medial orbital wall with replacement of ethmoidal cells.

Figure 8b- USG -demonstrates cystic nature \& differential diagnosis of mucopyocoele of lacrimal sac was offered.

The possibility of mucopyocoele of the lacrimal sac raised at $\mathrm{U} / \mathrm{S}$ in that case of ethmoidal mucocoele was ruled out by CT thus establishing its supremacy in such cases. Carcinomas arising from within the sinuses may invade the orbit and only CT can establish the true involvement. The extent of aggressive inflammatory lesions can also be established only by CT.

An interesting group of orbital lesions include cholesterol granuloma (chronic haematic cyst). It does not show typical features of a cyst. So ultrasound fails to demonstrate its nature. As they are bone destructive lesions, they are characterised better by CT.

\section{CONCLUSION}

Both modalities are complementary to each other in diagnosis of orbital space-occupying lesions. Since the clinical diagnosis often does not suggest the exact topography and nature of the lesion we believe that CT has to be performed first, often leading to an accurate final diagnosis when bony walls are involved. Sonography is the method of choice in diagnosis of intraocular lesions, but CT is needed to determine the true extent of the disease especially when they are malignant. Sonography is excellent for the diagnosis of optic nerve lesions and vascular masses, but it has to be supplemented with CT to delineate the extent of the mass. Sonography is an operator-dependent technique. CT is more accurate in characterising vascularity in extraocular lesions, including bony lesions, paraorbital lesions, cystic masses and paranasal sinus masses intruding into the orbit, but the radiation to the orbit has to be borne in mind.

Moreover, the mapping with CT is clearly more precise and reproducible. These images are very useful for the surgeon in deciding the surgical approach for reference during surgery.

\section{Limitations}

This is a single-centred study.

\section{REFERENCES}

[1] Grainger RG, Allison DJ. Grainger \& Allison's diagnostic radiology, a textbook of medical imaging. Volume 3, Churchill Livingstone, 1997:pp 2698.

[2] Haaga JR. CT and MRI of the whole body, a text book of computed tomography and magnetic resonance imaging of the whole body. Volume 2. Elsevier, 1994.

[3] Som P, Curtin H. A text book of head and neck imaging. Vol 1. Mosby, 1996:pp 1549.

[4] Grossman CB. Magnetic resonance imaging and computed tomography of the head and spine. $2^{\text {nd }}$ edn. Philadelphia, Williams \& Wilkins Baltimore, 1996.

[5] Aravind GN. Eye Care system. 3rd edn. Neuroophthalmology text book on Oct 1995.

[6] Peyman GA. Neuro-ophthalmolgy. In: Peyman GA. Principles and practice of ophthalmology. $1^{\text {st }}$ edn. Vol 2. Saunders (W.B.) Co Ltd, 1980:pp 1327-95.

[7] Salmon J, Bowling B. Kanski's clinical ophthalmology: a systematic approach. $5^{\text {th }}$ edn. Elsevier, 1986:pp 465-79.

[8] Berges 0, Vignaud J, Aubin ML. Comparison of sonography and computed tomography in the study of orbital SOL. AJN 1984;5(3):247-51.

[9] Kaufman LM, Mafee MF, Song CD. Retinoblastoma and simulating lesions. Role of CT and MR imaging and use of GD-DTPA contrast enhancement. Radiol Clin North Am 1998;36(6):1101-17.

[10] Forbes GS, Earnest F, Waller RR. Computed tomography of orbital tumours including late generation scanning techniques. Radiology 1982;142(2):387-94.

[11] Moseley IF, Sanders MD. Computed tomography in neuro-ophthalmology. $1^{\text {st }}$ edn. London, Chapman \& Hall 1982:pp 302.

[12] Enzmann D, Marshal WH, Rosenthal AR, et al. Computed tomography in Graves' ophthalmopathy. Radiology 1976;118(3):615-20.

[13] Harr DL, Quencer RM, Abrams GW. Computed tomography and ultrasound in the evaluation of orbital infection and pseudotumor. Radiology 1982; 142(2):395-401. 